\title{
ASSESSMENT ON DEFECTS OF WET-BLUE HIDE AND PICKLED SKIN AT MODJO TANNERY
}

\author{
Behailu Amde FELEKE ${ }^{1}$ and Yonas Gizaw HABTEMICHAEL ${ }^{2 \times 凶}$ \\ ${ }^{1}$ BSc, MSc, Federal Ministry of Livestock and Fisheries, Export Abattoirs Inspection and Certification Directorate, P.0. Box 62347 Addis Ababa, Ethiopia \\ 2DVM, MVSc; Jigjiga University, College of Veterinary Medicine, P.O.Box.1020 Jigjiga, Ethiopia \\ Email: yonasg5@gmail.com; (D) ORCiD: 0000-0003-4208-5682 \\ supporting Information
}

\begin{abstract}
Across-sectional study was conducted from February to June 2015 with the objectives of identifying the major types of hide and skin defects and determining their prevalence in pickled skins of sheep and wet blue goat skins and hides originated from two districts namely Hitosa and Dodota of East Arsi Zone at the Colba and Gelan tanneries in Modjo town. A total of 389 wet blue cattle hides, 385 wet blue goat skin and 399 pickled sheep skin were examined. The study finding showed that there exist various defects responsible for the decline in quality of skin and hide. The major defects at the wet blue hide were flay cut (59.1\%), gouge mark (42.2\%), and putrefaction (35.2\%). In sheep pickled skin higher percentage of cockle (36.9\%), gouge mark (28.3\%) and scratch $(27.0 \%)$ were observed. In wet blue goat skin, cockle (48.1\%), veininess $(44.6 \%)$ and crack (41.9\%) were the major defects observed. The prevalence of cockle, veininess, scar, corduroying, crack, gouge mark, poor pattern and brand mark were significantly higher $(P<0.05)$ in goat skin at wet blue stage than pickled sheep skin while putrefaction and shoat pox were significantly higher $(P<0.05)$ in sheep skin compared to goat wet blue skin. The major defects that leads to rejection of wet blue hide were flay cut while cockle in sheep and goat skin. In pickled sheep skin, grade of $1-3$ accounts $14 \%$ and grade $4-7$ accounts $86 \%$ of the total observation. This study showed large proportion of skin and hides were subjected to rejection because of poor quality and this implies that integrated efforts towards improved livestock husbandry and better health care are vital issues for production of better-quality hide and skin. Furthermore, effective extension system and programs that could raise public awareness on ectoparasites and skin diseases control as well as on methods of flaying, preservation and handling of skins should be implemented.
\end{abstract}

Keywords: Cockle, Fly cut, Grade, Hide, Quality, Rejection, Skin

Abbreviations: CSA: Central Statistical Authority; UNIDO: United Nations Industrial Development Organization; QSAE: Quality Standard Authority of Ethiopia; SPSS: Statistical Package for Social Science; FAO: Food and Agricultural Organization

\section{INTRODUCTION}

Ethiopia has $\mathbf{5 3 . 4}$ million cattle, $\mathbf{2 5 . 5}$ million sheep and $\mathbf{2 2 . 7}$ million goats. These numbers illustrate a considerable potential for the leather industry in the country (Central Statistical Authority, CSA, 2011/2012). This places the country as one of the richest countries in livestock resources. It has a huge potential for production of hide and skins. For instance, its potential was estimated at 3.78 million cattle hides, 8.41 million sheep skins and 8.42 million goatskins in $2012 / 13$ (CSA, 2013). This raw material of the leather industry is mainly derived from local areas of the country where basic amenities for slaughtering and subsequent marketing are either not in existence or lacking. Additional sources of hides and skins include slaughter slabs, municipal slaughterhouses and the limited number of export abattoirs. With regard to skin production, except the export abattoirs engaged in the production of chilled mutton and goat meat for export, the contribution of other slaughtering premises in terms of skin supply is very negligible (Ahmed, 2001).

The leather industry is one of the fastest-growing economic sectors in Ethiopia (Abadi, 2000; Bayou, 2007). The 26 operational tanneries in the country have a soaking capacity for 153,650 sheep and goat skins and 9,725 cattle hides per day (United Nations Industrial Development Organization (UNIDO, 2008). Nevertheless, they are not working to full capacity, as the hides and skins become available only when meat is needed and are not supplied for sustained leather processing (Bisrat, 2013).

The leather industry processes raw hides and skins and produces semi-processed and finished leather both for export and for local markets (Abadi, 2000). The semi-processed products are pickled sheep skin, wet blue goat skin and wet blue hides. Pickling denotes to treating unhaired, limed, delimed and bated hides or skins with a solution of salt and acid (e.g. sulphuric acid or formic acid) to preserve them or prepare them for the tanning process. Wet blue skins or hides refer to products that have been chrome tanned but not dried (Quality Standard Authority of Ethiopia, QSAE, 2008).

The leather industry sector is one of the growing Agricultural export commodities in Ethiopia. However, the sector is constrained by different factors like external parasites, inappropriate management of animals, faults during slaughtering 
and improper handling of skin before reaching to the tanneries. Hence the sector is losing large amount of money due to decline in quality and fall in export price (CSA, 2007). Lower quality hides and skins negatively impacts not only tanneries, but also Ethiopian footwear and other leather goods producers who sell their product domestically and abroad. There exists a paucity of research output in identifying pre and post-slaughter hide and skin causes of defects, and the measures to be taken under different agro-ecologies. To date there are no reports on type of defects on processed hides and skins in tanneries that sourced from East Arsi Zone especially Hitosa and Dodota districts which have high potential of livestock production. Therefore, this study was carried with the objective of identifying the major types of hide and skin defects and to determine their prevalence in pickled skins of sheep and wet blue goat skins and hides originated from the two districts of East Arsi Zone at the Colba and Gelan tanneries in Modjo town.

\section{MATERIALS AND METHODS}

\section{Study area}

The study was carried out at Colba and Gelan tanneries which are found in Modjo town. Modjo town is found in East Shoa Zone of Oromia Region, located $75 \mathrm{~km}$ south East of Addis Ababa situated between $8^{\circ} 35^{\prime} \mathrm{N}$ latitude and $39^{\circ} 10^{\prime} \mathrm{E}$ longitude at an altitude of 1,777 meters above sea level (CSA, 2008). Gelan tannery obtains the raw materials for processing from skin collection centers in and around the East Arsi Zone, Addis Ababa and Sheno and it has a soaking capacity of 2,000 sheep and 1,000 goat skins per day. Whereas, Colba tannery get cattle hide, sheep and goat skins from its main collection centers in East Arsi, Adama, Bishoftu, and Addis Ababa as well as from sheep and goats slaughtered in Modjo modern export abattoir which is a sister company of the tannery. It has a soaking capacity of 400 to 500 hides and 9,000 pieces of sheep and goat skins per day (Kebed and Yonas, 2015, Personal communication).

\section{Study design and sample size determination}

A cross-sectional study was conducted from February to June 2015 on skins and hides collected from the two districts of the East Arsi Zone namely Dodota and Hitosa after reaching and processed in their destination, cattle hide at wet blue stage in Colba tannery and sheep skin at pickle and goat skin at wet blue stage in Gelan tannery were randomly sampled and type of defect and their grading value were registered on pre-prepared data collection sheet. Systematic stratified sampling was used, whereby only $20 \%$ of each delivered batch was randomly selected and considered in this study. Each selected skin or hide was examined for defects in natural light by trained skin selectors of the company and the research groups (Figure 1). The defects were identified and graded according to the quality standards as indicated by the QSAE (2008). Various forms of skin defects appearing beyond $2.5 \mathrm{~cm}$ in sheep and goat skin and $5.0 \mathrm{~cm}$ in cattle hide from the edges towards the center of the skin were registered from grain and flesh surfaces.

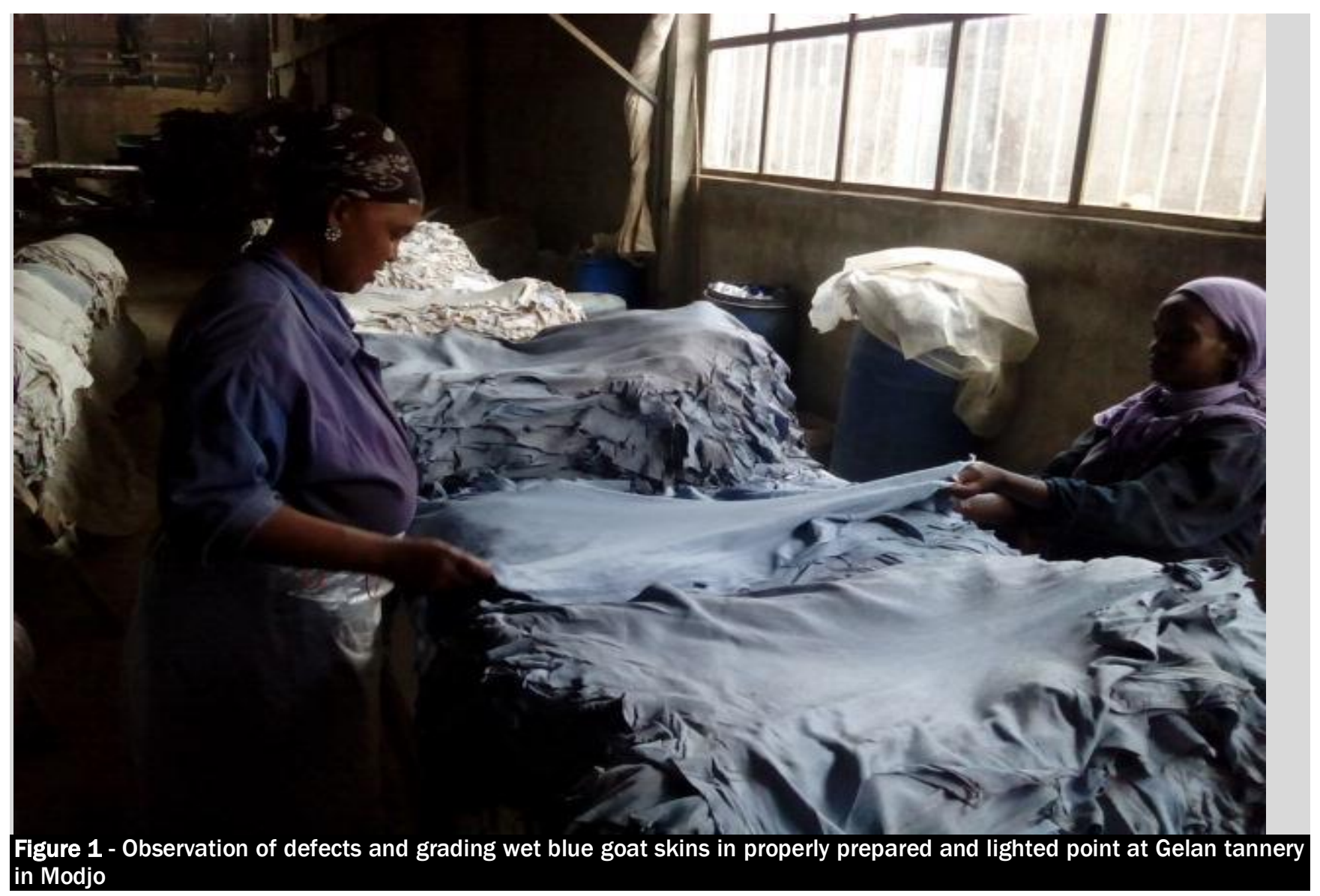


The total number of hide and skins included in the study was determined using the formula described by Thrusfield (2005). Based on the formula, with the assumption of $50 \%$ expected prevalence as there were no reports from study area, 95\% level of confidence (CL), and 5\% desired level of precision the sample size was calculated as 384 for skins of each animal species. Accordingly, 1,173 (389 cattle hide, 399 sheep and 385 processed goat skins) were selected for the study.

$$
\begin{aligned}
N=\frac{(1.96)^{2} P_{\exp }\left(1-P_{\text {exp }}\right)}{d^{2}} \quad \text { Where: } P_{\text {exp }} & =\text { expected prevalence }(50 \%) \\
n & =\text { required sample size } \\
d & =\text { desired absolute precision }
\end{aligned}
$$

\section{Statistical analysis}

Data collected were coded, entered, managed and stored into Microsoft Excel and imported to Statistical Package for Social Sciences (SPSS, version 20) software for analysis. Descriptive statistics were used to summarize the data with regard to frequencies and percentage. The Chi-square $\left(X^{2}\right)$ test were used to observe the association of different skin defects and species. Significance was considered at $P<0.05$.

\section{RESULTS}

\section{Defects on cattle hide at wet blue stage}

A total of 389 cattle hide were examined for the presence of defects after being processed in Colba tannery and all examined hides revealed one or more defects (Figure 2). The study showed higher prevalence of flay cut followed by gouge mark, putrefaction, corduroying, scratch, scar and cockle/ekeke (Table 1). The grade distribution of this study on wet blue cattle hide revealed that the higher grades, grade 1 accounts $8(2.1 \%)$, grade $2,8(2.1 \%)$, grade $3,18(4.6 \%)$ and the lower grades, grade 4 accounts $56(14.4 \%)$, grade $5,73(18.8 \%)$ grade $6,115(29.6 \%)$ and grade $7 /$ reject accounts 111 (28.5\%). Out of the total observed 389 hide $76.9 \%$ were distributed in the lower grades $5-7$, accordingly only few cattle hide went into first grades 1-3.

\section{Table 1 - Types of defects observed on hide at wet blue stage $(n=389)$}

\begin{tabular}{lcc} 
Type of defect & Frequency & Percent \\
\hline Flay cut & 230 & 59.1 \\
Gouge mark & 164 & 42.2 \\
Corduroying & 137 & 35.2 \\
Purification & 137 & 35.2 \\
Scratch & 110 & 28.3 \\
Scar & 78 & 20.1 \\
Cockle/ekeke & 49 & 12.6 \\
Brand mark & 25 & 6.4 \\
Machine defect & 22 & 5.7 \\
Wound & 21 & 5.4 \\
\hline
\end{tabular}

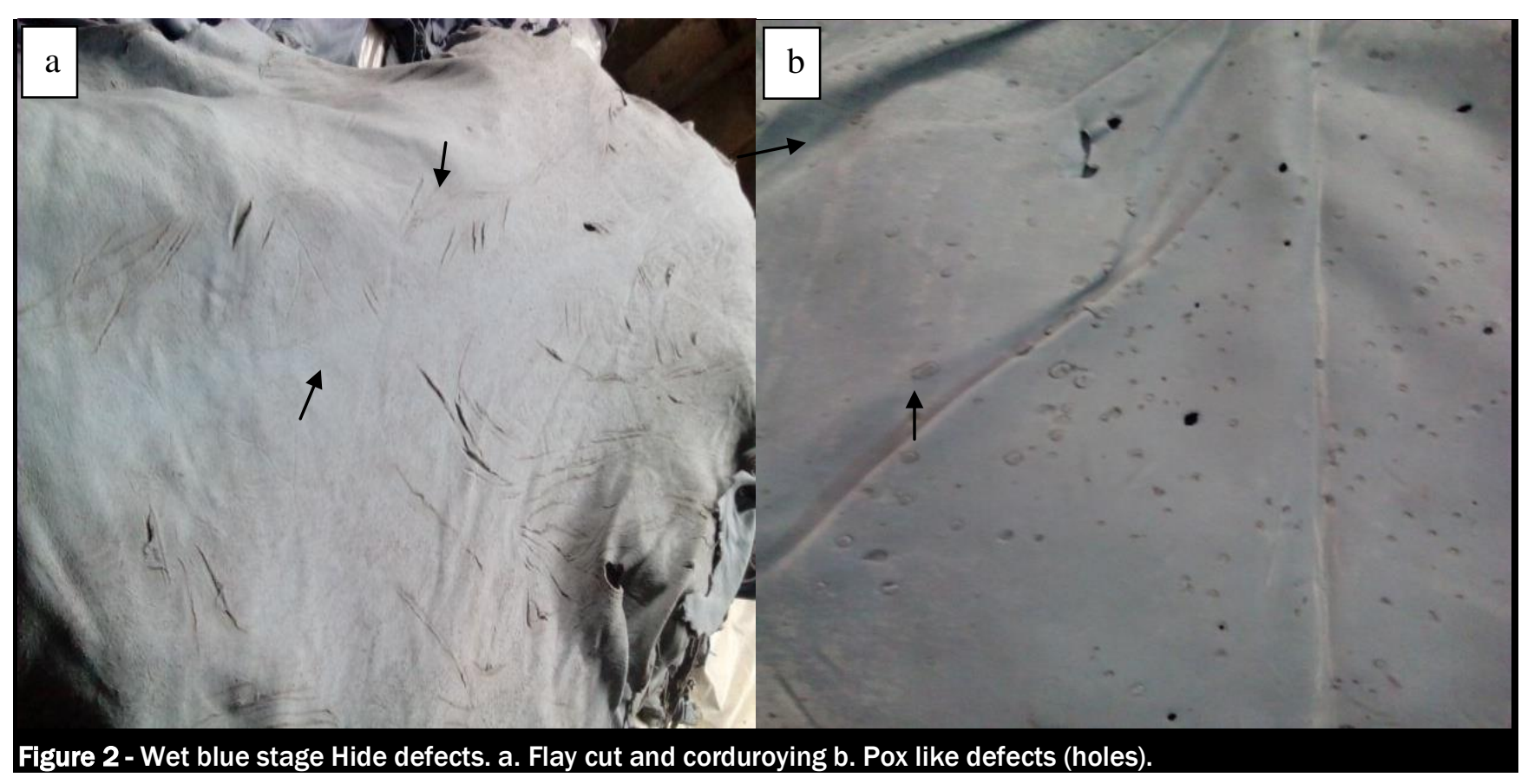




\section{Distribution of defects to hide quality grades}

The distribution of skin defects in different quality grades on cattle hide processed at wet blue stage is presented in Table 2. Flay cut was most important in quality grades 2 to 7 especially in quality grads 5 to 7 in a higher proportion comparing with the higher quality grades 1 to 3 . The other defects scratch, scar, pox, crack, brand mark and poor pattern were distributed in higher proportion in lower grades 4 to 7.

\section{Table 2- Distributions of defects on cattle wet blue stage in different grades}

\begin{tabular}{|c|c|c|c|c|c|c|c|c|}
\hline $\begin{array}{ll}\text { Type of defects } & \text { Grade } \\
\end{array}$ & 1 & 2 & 3 & 4 & 5 & 6 & 7/Reject & Total \\
\hline Cockle/'ekeke' & $0 *$ & 0 * & $0(0.0)$ & $1(0.9)$ & $2(1.2)$ & $14(4.6)$ & $32(8.0)$ & 49 \\
\hline Scratch & 0 & 0 & $4(16.7)$ & 12(11.9) & $16(9.8)$ & $30(9.8)$ & $48(12.0)$ & 110 \\
\hline Flay cut & 0 & $4(28.6)$ & $5(20.8)$ & $25(24.8)$ & $50(30.9)$ & $68(22.1)$ & $78(19.6)$ & 230 \\
\hline Scar & 0 & 0 & $4(16.7)$ & $3(3.0)$ & $7(4.3)$ & $29(9.4)$ & $35(8.8)$ & 78 \\
\hline Crack & 0 & 0 & 0 & $4(3.9)$ & $1(0.6)$ & $2(0.7)$ & $3(0.8)$ & 10 \\
\hline Corduroying & $3(27.3)$ & $3(21.4)$ & $4(16.7)$ & $13(12.9)$ & $30(18.5)$ & $44(14.4)$ & 40(10.0) & 137 \\
\hline Gouge mark & $5(45.5)$ & $2(14.3)$ & $3(12.5)$ & $27(26.7)$ & $27(16.6)$ & $53(17.3)$ & $47(11.8)$ & 164 \\
\hline Veniness & 0 & 0 & 0 & $1(0.9)$ & 0 & $2(0.7)$ & 0 & 3 \\
\hline Putrefaction & $2(18.2)$ & $3(21.4)$ & $3(12.5)$ & $5(5.0)$ & $13(8.0)$ & $45(14.7)$ & $66(16.6)$ & 137 \\
\hline Poor pattern & 0 & 0 & 0 & 2(1.9) & $3(1.9)$ & $2(0.6)$ & $4(1.0)$ & 11 \\
\hline Pox & 0 & 0 & 0 & 0 & 0 & 0 & $2(0.5)$ & 2 \\
\hline Machine defect & $11(9.0)$ & $1(7.1)$ & $1(4.2)$ & $3(2.9)$ & $2(1.2)$ & $5(1.6)$ & $9(2.3)$ & 22 \\
\hline Brand mark & 0 & 0 & 0 & $1(0.9)$ & $3(1.8)$ & $5(1.6)$ & $16(4.0)$ & 25 \\
\hline Poor pattern & 0 & 0 & 0 & 2(1.9) & $3(1.9)$ & $2(0.7)$ & $4(1.0)$ & 11 \\
\hline Wound & 0 & 1(7.1) & 0 & 2(1.9) & $4(2.5)$ & $4(1.3)$ & $10(2.5)$ & 21 \\
\hline Tick hole & 0 & 0 & 0 & 0 & $1(0.6)$ & $2(0.7)$ & $3(0.8)$ & 6 \\
\hline Total defects & 11 & 14 & 24 & 101 & 162 & 307 & 397 & 1016 \\
\hline
\end{tabular}

\section{Defects on pickled sheep skin and wet blue goat skin}

The prevalence of different defects on pickled sheep skin and wet blue goat skin examined in Gelan Tannery is presented in Table 3. On the assessment of sheep pickled skin, the study showed higher prevalence of cockle/ekeke, followed by gouge mark, scratch, flay cut, putrefaction, scare and crack. Whereas the prevalence of defects on goat wet blue skin according to their importance were cockle/ekeke, veininess, crack, scratch, gouge mark, flay cut, scar and corduroying. The prevalence of cockle/ekeke, veininess, scar, corduroying, crack, gouge mark, poor pattern and brand mark were significantly higher $(P<0.05)$ in goat skins while putrefaction and shoat pox were significantly higher $(P<0.05)$ in sheep skin at pickled stage than goat wet blue skin. On defects like scratch, flay cut, poor pattern and machine defect in sheep and goat skin there was no statistically significance $(P>0.05)$ difference.

The result of current study on proportion of skins in different quality grades of sheep and goat processed skin revealed that higher proportions of skins distribution in lower grades 4-7. Out of the total 385 pickled sheep skin observation the result showed that $0(0 \%)$ were in grade $1,7(1.8 \%)$ in grade $2,47(12.2 \%)$ in grade $3,85(22.1 \%)$ in grade $4,77(20 \%)$ in grade $5,80(20.8 \%)$ in grade 6 , and $89(23.1 \%)$ in grade $7 /$ reject. Moreover, the proportion of wet blue goat skin in different quality grade were 0 in grade $1,0(0 \%)$ in grade $2,1(0.3 \%)$ in grade $3,67(17.3 \%)$ in grade $4,135(33.8 \%)$ in grade 5, $107(26.8 \%)$ in grade 6 and $87(21.8 \%)$ were distributed in grade 7 . Significant number of skins in both species was classified as reject (Grade 7 ).

\section{Quality of sheep skin at pickled stage}

The distribution of skin defects in different quality grades on sheep pickled stage is presented in table 4. Ekek/cockle, scratch, scar, flay cut and venines were distributed from grade 2-7. Whereas corduroying, gouge mark, putrefaction, crack and poor pattern were distributed from grade 3-7. Moreover, cockle, flay cut and scratch were highly distributed in grade $7 /$ reject.

\section{Quality of goat skin at wet blue stage}

The distribution of skin defects in different quality grades on goat wet blue stage is presented in table 6 . Veinines was distributed from grade 3-7. Whereas cockle, scratch, flay cut, scar, crack, corduroying and putrefaction were distributed in the lower grades 4-7. Moreover cockle (ekek), scar, crack, scratch corduroying and gouge mark were highly distributed in grade $7 /$ reject. 
Table 3 - Proportion of defects between sheep and goat skins

\begin{tabular}{lccc} 
& \multicolumn{1}{c}{$\begin{array}{c}\text { Pickled Sheep } \\
\text { Types of defects }\end{array}$} & $\begin{array}{c}\text { Wet blue Goat skin } \\
(\mathbf{N}=399)\end{array}$ & P-value \\
\cline { 2 - 3 } & Number of defects (\%) & Number of defects (\%) & $192(48.1)$ \\
Cockle/ekeke & $142(36.9) * a$ & $0.001^{*}$ \\
Flay cut & $104(27.0)$ & $127(31.8)$ & 0.139 \\
Scar & $58(15.1)$ & $75(18.8)$ & 0.164 \\
Crack & $46(11.9)$ & $167(41.9)$ & $0.000^{*}$ \\
Corduroying & $22(5.7)$ & $150(37.6)$ & $0.000^{*}$ \\
Gouge mark & $44(11.4)$ & $166(41.6)$ & $0.000^{*}$ \\
Veniness & $37(9.6)$ & $79(19.8)$ & $0.000^{*}$ \\
Putrefaction & $38(9.9)$ & $178(44.6)$ & $0.000^{*}$ \\
Poor pattern & $58(15.1)$ & $14(3.5)$ & $0.000^{*}$ \\
Pox & $29(7.5)$ & $19(4.8)$ & 0.106 \\
Brand mark & $12(3.1)$ & $4(1.0)$ & $0.036^{*}$ \\
Machine defect & 0 & $14(3.5)$ & $0.000^{*}$ \\
Poor substance & $7(1.8)$ & $3(0.8)$ & 0.183 \\
Ring worm & $6(1.6)$ & 0 & $0.012^{*}$ \\
Tick hole & $2(0.5)$ & 0 & 0.149 \\
Wound & 0 & $1(0.3)$ & 0.326 \\
*p<0.05; *a Figures in parentheses are percentages & 0 & $1(0.3)$ & 0.326 \\
\hline
\end{tabular}

\section{Table 4 - Distribution of defects on sheep pickled stage in different quality grades}

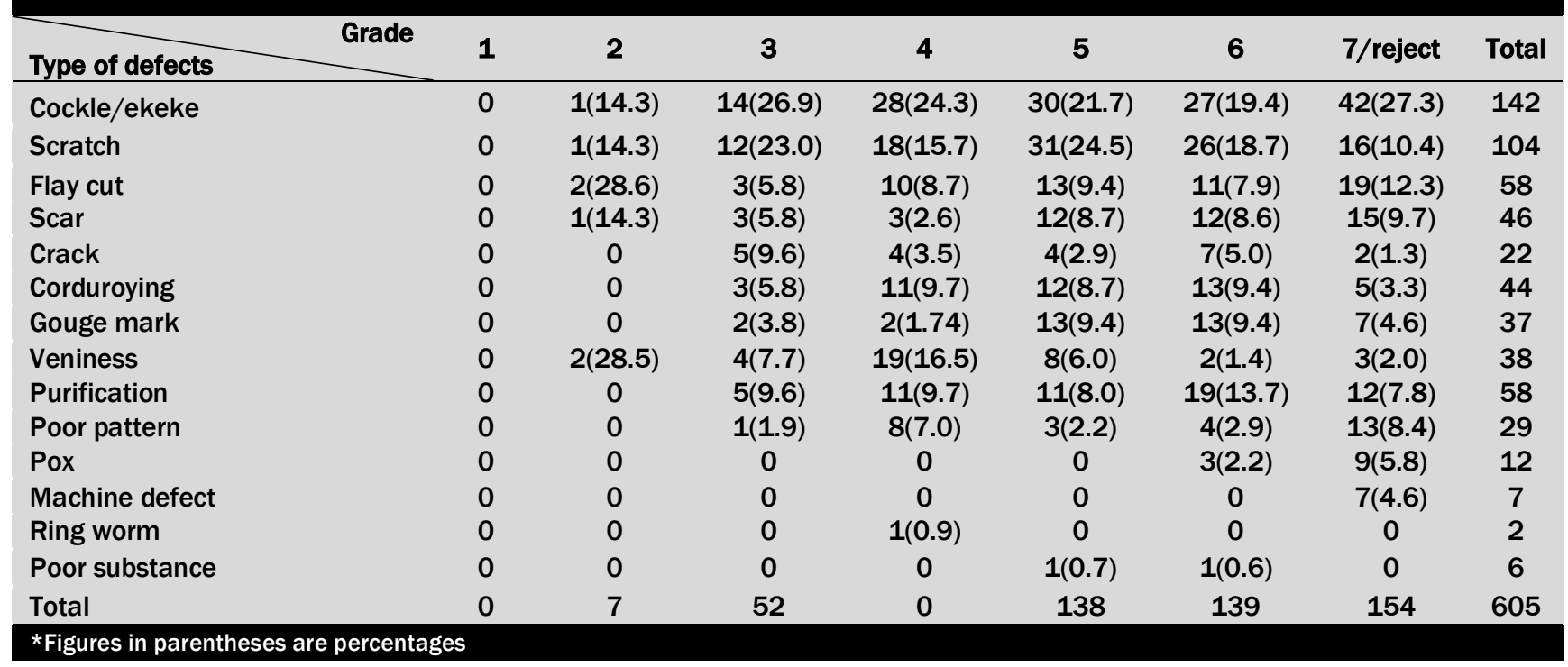

\section{DISCUSSION}

In the present study out of 389 cattle wet blue hide examined in Colba tannery, all hides had one or more defects. The various defects observed includes flay cut, gouge mark, putrefaction, corduroying, scratch, scar and cockle in their order of prevalence. This finding is in argument with the report by Bisrat (2013) who studied the case of tanneries in Addis Ababa and Modjo who reported lower prevalence of flay cut (21.3\%), putrefaction (15.8\%), scratch (13.5\%), branding $(2.5 \%)$ and scar $(0.3 \%)$. Likewise, present finding of $12.6 \%$ prevalence of cockle is also in contrary with report of Bisrat (2013) who reported higher percentage of cockle (42.5\%).

In the present study high proportion of wet blue hide grade lied in lower grades 4-7 which accounts $91.2 \%$ and the higher grades $1-3$ accounts only $\mathbf{8 . 8 \%}$ of the total observations. This finding is nearly similar with the report of Bisrat (2013) reported $99.6 \%$ of wet blue hide in grade 4-7 in Addis Ababa and Modjo tanneries. In contrary the present finding disagreed with his report which had very lower proportion in higher grade 1-3 (0.5\%). The current finding of low proportion of higher grade 1-3 is in agreement with the report of Mekonen and Gezahegn (2008) who indicated, the tanneries receiving raw hide and skin are often complaining the decline in the quality and quantity from time to time.

The present study on pickled sheep skin and goat wet blue skin defect assessment result showed a higher prevalence of cockle in goat (48.1\%) than sheep (36.9\%) skin which is in line with the findings of Worku et al. (2011) who reported $54.6 \%$ prevalence in goat and $45.4 \%$ in sheep from Modjo export tannery. On the contrary the current finding disagreed with the result of Zenaw and Mekonnen (2012) who reported that high prevalence of cockle (76\%) in pickled sheep than (22.4\%) in goat wet blue skin from Bahir Dar tannery. Furthermore, this study was not comparable with the findings of 
Hagos et al. (2013) who reported higher prevalence of cockle in sheep pickled skin (35\%) than goat wet blue (21.5\%) in Sheba tannery. In current study the higher prevalence of cockle/ekek in goat wet blue skin might be probably the direct reflection of high infestation of external parasites like mange, lice, flea in goat than sheep which were responsible for skin irritations and the mid altitude of the study area might not favorable for sheep ked which is common ectoparasite in sheep skin at higher altitude.

The higher prevalence of cockle in the present as well as other previous studies indicates the impact of cockle on the tanning industry is a serious concern. This is mainly due to the fact that cockle lesion cannot be detected at the raw skin and selection cannot be made prior to processing. The defect appears only after processing the skin into pickled stage. Therefore, the losses to the tanning industry is three times with regard to each cockle affected skins: first through the purchase of raw skins of undetectable inferior quality, secondly by the cost of processing of these skins and thirdly by the fact that such skins are downgraded after processing and therefore they are not suitable for sale in export markets (FAO, 1998; Kassa, 2006).

The current study revealed high prevalence of scratch (31.8\%) in goat wet blue stage than in sheep pickled (27.0\%) skin which were most important for downgrading of sheep and goat skin in Gelan tannery which is supported by Assefa et al. (2012), who reported a higher prevalence of scratch (73.3\%) in goat wet blue than sheep pickled skin (26.7\%) at Bahir Dar tannery and with that of Hagos et al. (2013) who reported higher prevalence of scratch (53\%) in goat wet blue than in sheep (43.4\%) pickled stage from Sheba tannery. However, the present finding was not in line with the findings of Worku et al. (2011) who indicated higher prevalence of scratch (57.3\%) in sheep pickled than goat wet blue (42.7\%) from Modjo export tannery. The higher prevalence of cockle and scratch on both pickled sheep and wet blue goat skin in the current study showed the association between cockle and scratch that could be attributed to the effect of ectoparasites on animals causing intense itching and rubbing against bushes, thorns, posts and barbed wires leading to the formation of scratches on their skin (Urquhart et al., 1996; Wall and Shearer, 1997).

A statistically significant higher prevalence of scar was observed in goat wet blue skin than sheep pickled skin. This finding is in line with report of Zenaw and Mekonnen (2012) who observed higher prevalence of scar in goat wet blue skin (15.2\%) than in sheep pickled skin (9.9\%).

Veinness / poor bleeding/ corduroying, gouge mark and brand mark which have statistically higher prevalence in goat wet blue skin than sheep pickled skins were the other important defects encountered in this study. Whereas, the prevalence of skin putrefaction in sheep pickled skin has higher than in goat. The higher prevalence of veniness or poor bleeding in goat was the most important defect in downgrading the wet blue skin of goats which was also observed in this study. This is in line with Alemu (2009) who observed the area with the congealed blood has a degrading effect to the leather quality. Veiny leather is the result of blood vessels in the skin where the blood is not completely drained (poorly drained). This is an unwanted effect which shows very clearly in suede leather. Veininess is a prominent defect in goat skins and very prominent in glazed kid leather.

The mentioned defects lead to downgrading or rejection of skins and hides. In this study, large proportion of sheep pickled skin are rejected. Grade 1-3 accounts only $14 \%$ and grade $4-7$ accounts $86 \%$ of the total observation. This finding is not in agreement with the study conducted of Bisrat (2013) who reported only (5.3\%) a proportion of 1-3 the higher grade and a proportion of lower grade 4-7(94.7\%) in Addis Ababa and Modjo tanneries. However, the present finding is in line with the report of Assefa et al. (2012) who reported 20\% proportion of higher grade/1-3 and $80 \%$ a proportion of lower grade/ 4-7. According to Mekonnen and Gezahegn (2008) the percentage of the highest-grade skins from grade 1-3 is very low in a randomly packed hides and skin on its arrival to the tannery. The present study confirmed that all defects have a high number of distributions in lower quality grades. Most of the sheep pickled skin defects were distributed under grade $7 /$ reject sheep pickled skins in order of importance were cockle/ekek, flay cut, scratch, scar, poor pattern, putrefaction and pox. The current finding is also supported by Kassa et al. (1998) stated that, as one quarter to one-third of all the skins processed at tanneries are unsuitable for export due to various defects.

The high proportions of goat wet blue skin were graded in the lower grades (4-7) of grade 5, grade 6, grade 7, grade 4, grade 3 in and none of the goat skins were in grade one and two confirming once more a very few proportions lied in grade 1-3. The present result is supported by the report of Bisrat (2013) who recorded a proportion of 1-3 the higher grade only (0.6\%) and a proportion of lower grade 4-7(99.4\%) in Addis Ababa and Modjo tanneries. Nevertheless, the present finding is not concords with the report of Assefa et al. (2012) which came up a proportion of higher grade/1-3 (5.6\%) and a proportion of lower grade/ 4-7(84.4\%) from Bahir Dar tannery. This difference between the two studies might be due to the variation in agro climate, management and the efficiency of ectoparasite control program conducted in the two study regions.

The most prevalent defects which leads to rejection (grade 7) of wet blue goat skin were cockle/ekek, scar, crack, and scratch. The present finding indicated that cockle were the dominant defects that leads to rejection of both wet blue goat and pickled sheep skin rejection. Similarly, scratch, scar and crack are also the cause for rejection or lower grade wet blue goat and pickled sheep skin. The present finding is accordance with the result of Berhanu et al. (2011) out of the rejected skins from goats and sheep, $98.8 \%$ of them had ekek or cockle and scratch, whereas $85.6 \%$ of them contained sheep and goat pox and $\mathbf{5 2 . 2 \%}$ of them were having knife cuts. Likewise, it is also comparable with the report of Assefa et al. (2012) which stated the most important defects in rejected skins were ekek/cockle (54.2\%), scratch (25\%) and pox (18.8\%). 
The study showed that all examined processed hide and skin originated from the two districts of East Arsi Zone had encountered one or more defect. Higher prevalence of various defects was observed, causing rejection of skin and hide. Such defects also cause depreciation in the value of the hides and skins and the consequence is that farmers, traders and the tanning industry suffer considerable financial losses. The low proportion of higher grades of 1-3 observed in this study is the direct reflections of poor live animal management (feeding, livestock disease managements), faulty animal slaughtering practices, post slaughter preservation, transportation of the hide and skins to the tanneries and as well as lack of agricultural extension services addressing hide and skin quality management. The higher prevalence of cockle on processed sheep and goats' skins demands attention to be given to external parasites control programs by the responsible stakeholders. Furthermore, effective extension system and programs that could raise public awareness on ectoparasites and skin diseases control as well as on methods of flaying, preservation and handling of skins should be implemented.

\section{DECLARATIONS}

\section{Consent to publish}

Not applicable

\section{Authors' contributions}

BA: Conception and design of the study, data collection, data analysis, draft writing and correcting the manuscript; YGH: Design of study, Data analysis and interpretation, revising the manuscript and final approval of the version for publication.

\section{Acknowledgements}

The authors would like to thank Hitosa and Dodota district animal production and health workers of for their logistic and appropriate expert's assistance during the field work. The authors also like to thank Colba and Gelan tanneries for their willingness to conduct this study in their company and passionate encouragement.

\section{Competing interests}

The authors declare that they have no competing interest.

\section{REFERENCES}

Abadi Y (2000). Current problems of the leather industry. In: Merkel RC, Abebe G and Goetsch AL (Editors), The opportunities and challenges of enhancing goat production in East Africa. Proceedings of a conference held at Debub University, Awassa, November 10-12, 2000, pp. 139-143. http://www./uresext.edu/.

Ahmed M (2001). Raw hides and skins improvement in Ethiopia: status and challenges. Proceeding of technical workshop on good practices for the Ethiopian hides and skins Industry held Addis Ababa, Ethiopia, December, 2001, pp. 20-22. Google Scholar

Alemu Y (2009). Common defects of sheep/goat skins in Ethiopia and their causes. Technical Bulletin, Number, 19. Ethiopia Sheep and Goat Productivity Improvement Program. R.C. Merkel (ed.). pp. 12. https://www.researchgate.net/publication/292149542.

Assefa M, Tesfaye D and Taye M (2012). A study on the prevalence of sheep and goat skin defects in Bahir Dar tannery, Ethiopia. Online Journal of Animal and Feed Research, 2: 384-387. http://www.ojafr.ir.

Bayou KT (2007). Hides, skins, and leather sector. In: Ethiopian Society of Animal Production (editors), Training manual for skin diseases of ruminant livestock in Ethiopia, USAID, Addis Ababa, Ethiopia, pp. 4-37. http://scholar.google.com/scholar.

Berhanu W, Negussie H, Alemu S and Mazengia H (2011). Assessment on major factors that cause skin rejection at Modjo export tannery, Ethiopia. Tropical Animal Health Production, 43: 989-993. DOI: https://dx.doi.org/1007/s11250-0119796-2.

Bisrat G (2013). Defect assessment of Ethiopian hide and skin: the case of tanneries in Addis Ababa and Modjo, Ethiopia. Journal of Global Veterinaria, 11: 395-398. DOI: https://dx.doi.org/10.5829/idosi.gv.2013.114.75182.

CSA (2007). Ethiopia agricultural sample enumeration, statistical report on livestock population. Part 4. Addis Ababa, Ethiopia: FDRE. http://www.csa.gov.et/survey-report/category/169-eth-agss.

CSA (2008). Agricultural Sample Survey 2007/08.Volume II. Report on livestock and livestock characteristics. Statistical Bulletin 417. Addis Ababa: FDRE. http://www.csa.gov.et/component/phocadownload/category/170-eth-agss.

CSA (2011/2012). Agricultural sample survey 2011/12. Volume II. Report on livestock and livestock characteristics. Statistical Bulletin 532. Addis Ababa: FDRE http://www.csa.gov.et/survey-report/category/127-eth-agss.

CSA (2013). Agricultural sample survey 2013. Report on Livestock and livestock characteristics. Statistical Bulletin 570. Addis Ababa: FDRE http://www.csa.gov.et/survey-report/category/129-eth-agss. 
FAO (1998). Control of sheep and goat skin diseases for improved hide and skins (phase II). lan B. C. and Bayou K. (editors). Proceedings on hide and skin improvement held in Addis Ababa, Ethiopia, February 22, 1998. FAO, Addis Ababa, Pp: 13-14. http://www.fao.org.

Hagos A, Yacob H and Mulugeta Y (2013). Impact of sheep and goats ectoparasites on the tanning industry in Tigray region. Ethiopian Veterinary Journal, 17: 63-76. DOI: http://dx.DOI.org/10.4314/evj.v17i2.5.

Kassa B (2006). Cockle, mange and pox: Major threats to the leather industry in Ethiopia. Perseverance towards value addition. Proceedings of the National leather industry workshop held in Addis Ababa, Ethiopia, December 14-15, 2006, Addis Ababa, Ethiopia. Google Scholar

Kassa B, Bisrat M and Assesgedech S (1998). Control of "Ekek" skin defect in sheep by insecticides and shearing. Proceedings of 12th Annual conference of EVA (Ethiopian Veterinary Association) held in Addis Ababa, Ethiopia. Google Scholar

Mekonnen B and Gezahegn A (2008). The Leather Sector: Growth Strategies through Integrated Value Chain: Research Report XI, Addis Ababa, Ethiopia. Ethiopian Development Research Institute. Google Scholar

Quality Standard Authority of Ethiopia (QSAE) (2008). Raw hides and skins: Grading of sheep and goat skins by appearance and mass (ES 1201: 2008), Quality Standard Authority of Ethiopia, Ethiopia.

FAO (1998): Skins. February 13-14, Addis Ababa, Ethiopia, Pp. 13-15.

Thrusfield M (2005). Veterinary Epidemiology, 3rd Edition. Blackwell Science Ltd., UK, pp. 229-245. Google Scholar

United Nations Industrial Development Organization (UNIDO) (2008). Technical assistance project for the upgrading of the Ethiopian leather and leather products industry (project number TE/ETH/08/008), UNIDO, Ethiopia. open.Unido.org

Urquhart GM, Armour J, Duncan JL, Dunn AM and Jennings FW (1996). Veterinary Parasitology, 2nd Edition. Blackwell Science Ltd., UK, pp. 141-205. ISBN: 0632040513

Wall R and Shearer D (1997). Veterinary Entomology, 1'st Edition. Chapman and Hall, UK, pp. 1-438. http://dx.doi.org/10.1007/978-94-01

Worku B, Haileleul N, Sefinew A and Hailu M (2011). Assessment on major factors that cause skin rejection at Modjo export tannery. Tropical Animal Health and Production, 43: 989-993. https://doi.org/10.1007/s11250-011-9796-2.

Zenaw Z and Mekonnen A (2012). Assessment of Major Factors That Cause Skin Defects. Journal Advances in Biological Research, 6: 177-181. DOI: https://dx.doi.org/10.5829/idosi.abr.2012.6.5.6636. 